\title{
Resistance of Commensal Intestinal Escherichia Coli and Other Enterics to Co-trimoxazole and Commonly Used Antibiotics in HIV/AIDS Patients
}

\author{
Kennedy D Mwambete* and Appolinary AR Kamuhabwa
}

Muhimbili University of Health and Allied Sciences, School of Pharmacy, Department of Pharmaceutical Microbiology and Unit of Pharmacology \& Therapeutics, Tanzania

\begin{abstract}
Trimethoprim-sulfamethoxazole (CTX) has been recommended by the World Health Organization as a prophylactic drug for HIVIAIDS-patients against opportunistic infections. However, daily use of CTX may reduce its efficacy to enteric Escherichia coli, thus increasing the burden of CTX-resistant pathogens. Resistance of enteric pathogens to CTX may affect empiric treatment approaches especially in HIVIAIDS patients. We prospectively investigated incidences of fecal E. coli resistance to CTX in $188 \mathrm{HIV-infected} \mathrm{patients} \mathrm{of} \mathrm{15-72} \mathrm{years} \mathrm{of} \mathrm{age,} \mathrm{and} \mathrm{determined}$ changes in susceptibility patterns. The study was conducted in Dar es Salaam, Tanzania involving collection of stool specimens from HIV-patients prior and after initiation of CTX prophylaxis. Specimens were collected on $1^{\text {st }}, 4^{\text {th }}$, and $24^{\text {th }}$ weeks upon commencing CTX prophylaxis. Susceptibility profiling of $E$. coli and other enteric bacteria to CTX and other widely used antibiotics were done using Kirby-Bauer disk diffusion method. On the first visit, 143(76.1\%) enteric bacteria were isolated. Of those, $123(86 \%)$ were E. coli. About $98.6 \%$ were resistant to CTX. On the second visit, $103(54.2 \%)$ bacteria were isolated; of those, $100(98.4 \%)$ of them exhibited resistance to CTX. On the third visit, $64(34 \%)$ out of 188 patients had significant enteric bacteria, and of those $63(98.4 \%)$ were resistant to CTX. About $53.2 \%$ of bacterial isolates were resistant to ciprofloxacin and ampicillin. Majority $(95.2 \%)$ of the patients had initiated CTX prophylaxis prior to testing at the care and treatment clinics. About $32 \%$ of the patients reported to have skipped some doses of CTX prophylaxis. Non-adherence to CTX prophylaxis and self-medication among patients may have attributed to the observed high prevalence rate of $E$. coli resistance to CTX and other commonly used antibiotics. For better understanding of the observed pattern of bacterial resistance to CTX, phenotypic and/or genotypic characterization of the isolated bacteria needs to be conducted.
\end{abstract}

Keywords: Antibacterial resistance; Enteric bacteria; HIV/AIDS patients; Co-trimoxazole prophylaxis

\section{Introduction}

Trimethoprim-sulfamethoxazole (CTX) is the most efficacious drug against non-typhoid Salmonella (NTS) bacteraemia particularly Salmonella typhimurium and Salmonella enteritidis, which are known to be the leading cause of morbidity and mortality in HIV infected patients in Africa [1,2]. Prophylaxis for opportunistic infections (OIs) with CTX has also been shown to reduce mortality and morbidity among HIV infected patients with sputum positive tuberculosis (TB) in several countries [3-5].

Antimicrobial resistance is a growing problem and a cause of great concern throughout the world [6-9]. Unlike higher organisms, bacteria can transfer DNA to other bacteria which are not their off-springs, and even to members of completely unrelated bacterial species. Hence, there is a general consensus on the existence of a high degree of rapid plasmid mediated transfer of CTX resistance between faecal E. coli and the Salmonella species as well as other Enterobacteria [10,11]. The level of faecal E. coli resistance to CTX would therefore cause similar resistance patterns in NTS and other bacteria. Antibiotic resistance carries a significant economic toll as well as a medical burden [12]. The WHO Office of Technology Assessment estimates that resistance in just six types of bacteria increased hospital treatment costs by billions of US dollars [13].

The growing health crisis of antibiotic resistance could render these important drugs ineffective in treating infections. The Centre for Disease Control (CDC) and Prevention has observed that "decreasing inappropriate antibiotic use is the best way to control resistance" [14]. Key steps in doing so include adoption of policies aimed at ending the inappropriate use of antibiotics in agriculture, as well as continued implementation of programs to educate patients and physicians about the need to use antibiotics more cautiously. Unless we act now, we face a future of untreatable bacterial infections. Immune-compromised patients such as people living with HIV/AIDS (PLHA) are the most likely to be affected by resistant bacterial and fungal infections.

As in many other developing countries, conditions that may foster antibiotic resistance in Tanzania differ from developed countries, and so resistance prevalence. Faecal pollution and other traits of overcrowded cities with poor sanitary conditions might create ideal settings for selecting, exchanging and maintaining resistance traits. In addition, medical abuse of antibiotics, along with low-quality drugs are also prevalent [13]. Self-medication, a common yet unmeasured practice among Tanzanian population, may also contribute to increased resistance rates [15]. Therefore, knowledge of antimicrobial resistance trends among bacterial isolates is essential in order to provide clinically appropriate and cost effective therapy.

Microbial infections such as NTS and Salmonella food-borne infections are particularly common problems for HIV/AIDS patients in Tanzania. HIV-infected patients are at greater risk of developing

*Corresponding author: Kennedy D Mwambete, Muhimbili University of Health and Allied Sciences, Department of Pharmaceutical Microbiology, Tanzania, Tel: +255787508782; Fax: +255-(0) 22-2150465; E-mail: kmwambete@muhas.ac.tz

Received October 18, 2013; Accepted December 13, 2013; Published December 28, 2013

Citation: Mwambete KD, Kamuhabwa AAR (2013) Resistance of Commensal Intestinal Escherichia Coli and Other Enterics to Co-trimoxazole and Commonly Used Antibiotics in HIVIAIDS Patients. Clin Microbial 3: 134. doi:10.4172/23275073.1000134

Copyright: ( 2013 Mwambete KD, et al. This is an open-access article distributed under the terms of the Creative Commons Attribution License, which permits unrestricted use, distribution, and reproduction in any medium, provided the original author and source are credited. 
serious food-borne bacterial infections; therefore they have to take antibiotics daily to prevent recurrent infection of the bloodstream (septicaemia). CTX use had been implicated in development of CTX resistant Streptococcus pneumonia [16], but much less is known about development of resistance in gram-negative bacteria like E. coli, organisms for which CTX plays an important therapeutic role in HIVinfected patients.

\section{Methodology}

\section{Study setting}

The study was conducted in the three municipal hospitals in Dar es Salaam, which are Mwananyamala, Amana and Temeke hospitals. Apart from Muhimbili National Hospital which is a referral hospital, the three municipal hospitals are the major public hospitals providing care and treatment services for PLHA in Dar es Salaam, Tanzania. Patients over 18 years of age undergoing voluntary counselling and HIV testing with CD4 cell count of $\leq 350$ cells $/ \mathrm{mm}^{3}$ are eligible to start CTX prophylaxis for opportunistic infections and were recruited in the study.

Pregnant women in their first trimester were excluded at each visit using a menstrual history and urine pregnancy test. Pregnant women in their second or third trimester were included in the study [17]. Patients below 18 year of age were also excluded from the study, unless parents' or guardians' verbal or written consent were obtained.

\section{Study population and specimen collection}

Stool specimens were collected immediately after registration and before starting CTX therapy. Information was sought to whether prior to registration at the CTC, any of the patients would have been using CTX for any particular disease condition. To compare and determine whether there would be changes in CTX resistance with time, three serial cross-sectional resistance studies were carried out using stool specimens collected from cohorts of newly registered patients selected randomly before commencement of CTX medication.

The CTX prophylaxis was given in form of 2 single-strength tablets, each containing $80 \mathrm{mg}$ of trimethoprim and $400 \mathrm{mg}$ of sulfamethoxazole, daily. Patients were categorized into two groups: patients who have been using CTX prior to registration at the CTC for over 3-6 months and those who were initiated CTX prophylaxis during the time of the study (naive). A structured questionnaire was used to gather information on the basic socio-demographic data.

\section{Laboratory procedures}

Whole stool was collected at the baseline visit and before administration of the first dose of CTX for all participants. Participants were then requested to return to the clinics on the $1^{\text {st }}, 4^{\text {th }}$, and $24^{\text {th }}$ weeks after the baseline visit. At each visit, whole stool was collected and the standardized clinical history and physical examination were repeated. Adherence to CTX prophylaxis was assessed at each follow-up visit by patient self-report.

Whole stool was inoculated onto MacConkey agar with CTX disk and incubated for 24 hours at $37^{\circ} \mathrm{C}$. Plates were examined for the presence of flat, dry, lactose-utilizing colonies consistent with $E$. coli. The presence or absence of presumptive $E$. coli was recorded. If colonies consistent with E. coli (ATCC 25922, American Type Culture Collection, Rockville, MD) on regular basis were not observed within $<16 \mathrm{~mm}$ of the CTX disk, the stool was classified as having susceptible E. coli. For colonies consistent with E. coli that appear within $<16 \mathrm{~mm}$ of the CTX disk, the stool was classified as having non-susceptible
E. coli as per recommendations $[18,19]$. Colonies nearest to the disk were picked and sub-cultured to blood agar. The inoculated blood agar or MacConkey plates were incubated for 24 hours at $37^{\circ} \mathrm{C}$, and biochemical tests [oxidase and indole tests, sugars fermentation or/ and serological test (H\&K antigens)] were performed on the resulting growth for confirmation of the isolates [20].

\section{Testing of antimicrobial susceptibility to commonly used antibiotics}

Anti-microbial susceptibility testing was done on Mueller-Hinton agar plates. Susceptibility testing for ampicillin and ciprofloxacin were done using the Kirby-Bauer disk diffusion method [21]. For the isolated bacteria viz. Staphylococcus aureus, Klebsiella spp and E. coli interpretive criteria were used to evaluate zone sizes for ciprofloxacin and ampicillin based on the antibiograms for standardised control strains of E. coli (ATCC 25922) and S. aureus (ATCC 25923).

\section{Data analysis}

Statistical data analysis was done using a descriptive analysis of the subjects comparing changes in the proportion of $E$. coli nonsusceptibility to CTX over time and assessment of the effect of CTX use on co-selection of non-susceptibility to other antimicrobial agents (ciprofloxacin and ampicillin). The Statistical Package for Social Sciences (SPSS, version 17.0) was used for descriptive analysis, independentsamples T-test for comparison of means of CD4 count, correlation and multinomial logistic regression among various dependent and predictor variables. Differences of assessed parameters among various sets of data were considered significant at $\mathrm{p}<0.05$.

\section{Ethical consideration}

The study was granted ethical clearance by the Muhimbili University of Health and Allied Sciences Ethical Committee. Permission to conduct the study in the selected health facilities was sought from the Municipal Medical Officers in-charge. Following a written informed consent from the study participants, a standardized clinical history and physical examination were carried out. Patients were also informed that all the information gathered and laboratory results would be used for research purpose, but could be available for any participant who would wish to know the findings. In order to maintain confidentiality data were entered into the computer for analysis and interpretation by using code numbers.

\section{Results}

\section{Demographic characteristics of the study participants}

A total of 188 patients were recruited in this study. Out of those, $80(42.6 \%)$ were males and $108(57.4 \%)$ females, with age ranging from 15 to 72 years and median of 37 years of age. Majority $(75.5 \%)$ of the participants had no formal education. A total of 60 (31.9\%) patients were recruited at Amana, 63(33.5\%) at Mwananyamala and 65(34.6\%) at Temeke Municipal hospitals (Table 1).

\section{Prevalence of opportunistic infections and correlation with CD4 cell count in patients}

About half (51.1\%) of patients were experiencing OIs. Of those OIs, $55 \%(n=53)$ were due to TB and 22(23\%) were of fungal origins. The patients CD 4 cell counts ranged from 4 to 1044 cells/ $\mu$, with median of 232 cells $/ \mu$ l. About $51.6 \%$ of the patients had 201-350 CD4 cell counts, while $74(39.4 \%)$ had CD4 cell count of $<200$. Nevertheless, $36(43 \%)$ of the patients with $\mathrm{CD} 4$ cell count of $<200$ did not experience OIs during 


\begin{tabular}{|l|l|c|c|c|c|}
\hline \multirow{2}{*}{ Variables } & \multicolumn{3}{|c|}{ Care and treatment centres } & \\
\cline { 3 - 6 } & & Amana & Mwananyamala & Temeke & Total (\%) \\
\hline \multirow{3}{*}{ Gender } & Males & 25 & 27 & 28 & $80(42.5)$ \\
\cline { 2 - 6 } & Females & 35 & 36 & 37 & $108(57.5)$ \\
\hline \multirow{5}{*}{ Age group } & $15-30$ & 17 & 15 & 16 & $48(25.5)$ \\
\cline { 2 - 7 } & $31-46$ & 31 & 39 & 36 & $106(56.4)$ \\
\cline { 2 - 7 } & $47-62$ & 11 & 8 & 12 & $31(16.5)$ \\
\hline \multirow{5}{*}{ Education level } & $>62$ & 1 & 1 & 1 & $3(1.6)$ \\
\cline { 2 - 7 } & Informal & 42 & 49 & 51 & $142(75.5)$ \\
\cline { 2 - 7 } & Simary & 3 & 8 & 6 & $17(9.0)$ \\
\cline { 2 - 7 } & Secondary & 2 & 1 & 2 & $5(2.7)$ \\
\hline & College & 13 & 5 & 6 & $24(12.8)$ \\
\hline
\end{tabular}

Table 1: Socio-demographic characteristics of patients who were recruited in the study.

\begin{tabular}{|c|c|c|c|c|c|c|c|}
\hline \multirow[t]{2}{*}{ Ols } & \multirow[t]{2}{*}{$\begin{array}{l}\text { CD cell counts } \\
\text { (cells/ } / \mu \text { ) }\end{array}$} & \multicolumn{5}{|c|}{$\begin{array}{l}\text { Duration of CTX prophylaxis } \\
\text { (months) }\end{array}$} & \multirow[t]{2}{*}{ Total (\%) } \\
\hline & & $>24$ & 24 & $>6$ & $<6$ & $<3$ & \\
\hline \multirow{4}{*}{ Present } & $1-200$ & 19 & 10 & 5 & 2 & 2 & $38(20.2)$ \\
\hline & $201-350$ & 24 & 6 & 7 & 2 & 8 & $47(25.0)$ \\
\hline & $351-500$ & 3 & - & 3 & 1 & - & $7(3.7)$ \\
\hline & $>501$ & 2 & - & 1 & - & 1 & $4(2.1)$ \\
\hline \multirow{3}{*}{ None } & $1-200$ & 17 & 5 & 6 & 2 & 6 & $36(19.1)$ \\
\hline & $201-350$ & 34 & 5 & 3 & 3 & 5 & $50(26.6)$ \\
\hline & $351-500$ & 2 & 1 & 1 & 2 & - & $6(3.2)$ \\
\hline
\end{tabular}

Table 2: Occurrence of opportunistic infections in relationship to the levels of CD4 cell count and duration of CTX prophylaxis in HIV infected patients $(n=188)$.

the time of the study. It was also found that $4(2.1 \%)$ patients with CD4 cell count over 501 had OIs (Table 2).

The study also revealed that all patients had been on CTX prophylaxis for different period of time. There was a positive association between the duration of CTX use and CD4 cell count among patients $(\mathrm{r}=0.0 .17 ; \mathrm{p}=0.817)$. About $54 \%(\mathrm{n}=101)$ of patients were on CTX prophylaxis for more than a year. Out of these, 53 (52.5\%) were not experiencing OIs, despite the fact that 17 (17\%) of them had CD4 cell count below 200 (Table 2).

Regarding the level of CD4 cell counts, no significant differences were observed between patients with OIs and those without OIs $(\mathrm{p}=0.538 ; \mathrm{df}=187 ; \mathrm{F}=5.597)$. Comparison of the number of OIs per patient between CTX users and non-users, revealed no significant differences $(\mathrm{p}=0.512 ; \mathrm{df}=176 ; \mathrm{F}=2.655)$. However, CTX users were 1.2 times less likely to acquire OIs than non-users $(\mathrm{p}<0.05)$.

A negative correlation between CD4 cell counts and number of OIs was observed $(r=-0.021 ; p=0.391)$. Though not statistically significant, this observation was complemented by the regression coefficient (Standardized Beta $=-0.029 ; \mathrm{p}>0.05$ ). A slight correlation though not statistically significant was also evident between the period of exposure to CTX prophylaxis and CD4 cell counts $(r=0.017 ; \mathrm{p}=0.409)$. Figure 1 shows some of the common OIs among the study participants in relationship to CD4 cell count and sex of patients.

\section{Adherence patients to CTX prophylaxis for opportunistic infections}

Of 188 patients, majority $(95.2 \% ; n=179)$ of them had been on CTX prophylaxis prior to registration at the CTC. Of 179 patients on CTX prophylaxis, $57(32.0 \%)$ had skipped some CTX prophylaxis regimens due to various reasons. Twenty two $(12.3 \%)$ of patients who admitted to have had skipped doses of CTX prophylaxis had CD4 cell count of 1-200 as compared to $40(22.3 \%)$ patients with the same amount of CD4 cell count who reported to be adherent. Among patients with CD4 cell count of 201-350, 17.3\% of them had skipped doses of CTX on several occasions, while $45(25 \%)$ patients mentioned that they had never skipped the dose of medication. Ten patients (5.3\%) in the category of CD4 cell count of 1-200 and 17 with CD4 cell count of 201-350 could not recall if they ever had skipped doses of CTX prophylaxis.

The most cited reasons for non-adherence were unavailability of CTX at the hospitals (35\%) and CTX induced side effects (27\%). Other reasons for non-adherence were forgetting to take the medication at the pre-determined time and frequency $(18 \%)$, travelling and therefore not able to visit CTCs for prescription refill (12\%) and burden of pills due to concomitant use of CTX with other medications including ARVs and other drugs for OIs (4\%).

Ten $(5.3 \%)$ out of 188 patients who admitted to have had altered the dose and frequency of use of the medication, only 3 of said it was due to CTX side effects. However, out of $161(85.6 \%)$ patients who claimed not to have had changed the use of medication, 23(14.3\%) of them had experienced several side effects as indicated in Figure 2.

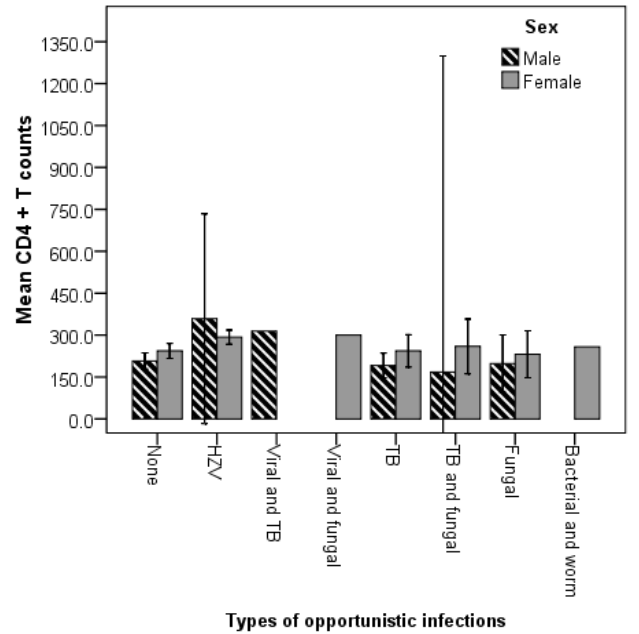

Figure 1: Common opportunistic infections experienced by HIV-infected patients in relationship to CD4 cell count levels (Error bars: $95 \%$ confidence of interval).

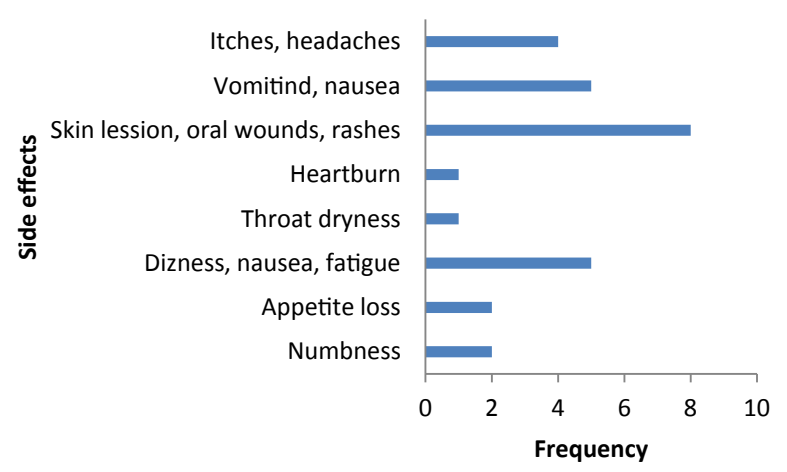

Figure 2: CTX-induced side effects as reported by HIV-infected patients using CTX prophylaxis for opportunistic infections $(n=26)$. 


\begin{tabular}{|c|c|c|c|c|c|c|}
\hline \multirow{2}{*}{ Visits } & \multirow{2}{*}{ Remarks } & \multicolumn{4}{|c|}{ CD4+ T cell counts } & \multirow[t]{2}{*}{ Total (\%) } \\
\hline & & $1-200$ & $201-350$ & $351-500$ & $501-1200$ & \\
\hline \multirow[t]{4}{*}{ Start } & NA & - & - & 2 & - & $2(1.1)$ \\
\hline & s & 15 & 14 & 3 & 4 & $36(19.1)$ \\
\hline & $\mathrm{R}$ & 59 & 83 & 8 & 0 & $150(79.8)$ \\
\hline & & & & & & $\mathrm{R}(80.6)$ \\
\hline \multirow[t]{4}{*}{$1^{\text {st }}$ week } & NA & 20 & 23 & 2 & - & $45(23.9)$ \\
\hline & $s$ & 1 & 0 & 0 & 1 & $2(1.1)$ \\
\hline & $\mathrm{R}$ & 53 & 74 & 11 & 3 & $141(75.0)$ \\
\hline & & & & & & $\mathrm{R}(98.6)$ \\
\hline \multirow[t]{4}{*}{$4^{\text {th }}$ week } & NA & 32 & 42 & 8 & 3 & $85(45.2)$ \\
\hline & $\mathrm{s}$ & 1 & 2 & 0 & 0 & $3(1.6)$ \\
\hline & $\mathrm{R}$ & 41 & 53 & 5 & 1 & $100(53.2)$ \\
\hline & & & & & & $\mathrm{R}(97.1)$ \\
\hline \multirow[t]{4}{*}{$24^{\text {th }}$ week } & NA & 50 & 61 & 10 & 3 & $124(66.0)$ \\
\hline & $S$ & 0 & 1 & 0 & 0 & $1(0.5)$ \\
\hline & $\mathrm{R}$ & 24 & 35 & 3 & 1 & $63(33.5)$ \\
\hline & & & & & & $\mathrm{R}(98.4)$ \\
\hline Total & & 74 & 97 & 13 & 4 & $188(100.0)$ \\
\hline
\end{tabular}

Key: NA-no isolate; R-resistant to CTX; Sensitive to CTX.

Table 3: Susceptibility of the E. coli isolates to CTX in relation to patient's CD4 cell count $(n=188)$

\begin{tabular}{|l|c|c|c|c|c|c|c|c|c|}
\hline \multirow{2}{*}{ Antibiotics } & \multicolumn{9}{|c|}{ Isolated microbes } \\
\cline { 2 - 11 } & \multicolumn{3}{|c|}{$\mathbf{1}^{\text {st }}$ Week } & \multicolumn{2}{c|}{$\mathbf{4}^{\text {th }}$ week } & $\mathbf{2 4}^{\text {th }}$ week & Total \\
\cline { 2 - 10 } & Eco & Sta & Kle & Eco & Sta & Kle & Eco & Sta & N=188 \\
\hline Cipro (S) & 45 & - & 1 & 1 & - & - & - & - & $47(25.0)$ \\
\hline Cipro, Amp (S) & 2 & - & - & 1 & - & 1 & 1 & - & $5(2.7)$ \\
\hline Cipro (S), Amp (R) & 37 & 3 & 1 & 22 & 7 & 2 & 7 & - & $79(42.0)$ \\
\hline Amp (S), Cipro (R) & 1 & - & - & 1 & - & - & 5 & 2 & $9(4.8)$ \\
\hline Cipro, Amp (R) & 30 & 3 & - & 14 & 5 & 2 & - & 3 & $60(31.9)$ \\
\hline
\end{tabular}

Key: S-sensitive; R-resistant; Eco-E. coli, Sta-S. aureus; Kle-Klebsilla spp; Ampampicillin; Cipro-ciprofloxacin.

Table 4: Susceptibility patterns of two commonly used antibiotics on the isolated bacteria from stool of HIV infected patients $(n=188)$.

\section{Susceptibility profiling of isolated microbes}

A total of 186 bacteria were isolated from patients prior to commencing the CTX prophylaxis study. The bacteria were comprised of $121(65 \%)$ E. coli, 28 (15\%) S. aureus and $20 \%$ were other enterics. Of these bacteria, 150(80.6) were resistant to CTX (Table 3). During the first week of visit: a total of $143(76 \%)$ isolates (E. coli, S. aureus, Klebsiella) were obtained from 188 patients. Of those, majority were E. coli. Significant number of the isolates $(98.6 ; n=141)$ were resistant to CTX. In the second visit ( $4^{\text {th }}$ week); a total of 103 bacteria were isolated and identified, of those $76(74 \%)$ were E. coli while $63(97 \%)$ of the isolates were resistant to CTX. Of 103 tested isolates, 100(97.1) were resistant to CTX. In the last visit (24 $4^{\text {th }}$ week); only $64(34 \%)$ bacteria were isolated from 188 patients. Of those, E. coli constituted $61 \%$ of the isolates. About $98.4 \%(n=63)$ of the isolates were resistant to CTX. The antibiotic susceptibility profiles for ciprofloxacin (Cipro) and ampicillin (Amp) are summarized in Table 4.

\section{Effect of CTX prophylaxis on the prevalence of OIs in HIV-} infected patients

For every one unit decrease in CD4 cell count there was likelihood of 0.03 increase for occurrence of OIs $(\mathrm{p}=0.702)$. For patients who did not use CTX the possibility of getting OIs was 0.14 times higher than those who were on CTX prophylaxis. Those who were non-adherent to CTX prophylaxis regimens had 0.16 higher chances of developing OIs, which is 1.17 times than those who did not skip any of the prescribed doses $(p=0.718)$. Similarly, a negative association was observed between the quantity of medication taken and occurrence of OIs in patients $(\mathrm{r}=-$ $0.060 ; \mathrm{p}=0.216)$. This is an indication that more drugs apart from CTX were needed to manage OIs in patients as time progressed.

Comparative analysis of the association between the number of OIs and CD4 cell counts with respect to patients' sex revealed that males were 1.36 times $(\mathrm{p}=0.309)$ less likely to have OIs as compared to females; though the differences were statistically not significant.

\section{Discussion}

CTX contains two main antimicrobial active ingredients, i.e. sulfamethoxazole and trimethoprim. Given together, these antimicrobial agents provide good coverage against a wide range of bacteria such as Streptococcus pneumoniae, Escherichia coli and nontyphoid Salmonella, protozoa (Isospora belli, Toxoplasma gondii and Plasmodium falciparum) as well as fungi especially Pneumocystis jirovecii [22]. According to the results of earlier studies, CTX may decrease both mortality and morbidity in adults with HIV infection, regardless of the use of ART [23-25].

The results of this study show an overall high (93.7\%) resistance rate to CTX among the isolated enteric E. coli. These findings are similar to those reported by other researchers [26,27]. Many factors may be the reasons for the high prevalence of $E$. coli resistance to CTX. In Tanzania, CTX tablets and syrups are readily available in the retail pharmacies and health facilities. Although easy availability improves access to the drug, this also may contribute to irrational use of the medicine through self-medication. This is most likely to happen in PLHA who may be using the drug for management of OIs without proper guidance from qualified health care workers. Another reason for high resistance of $E$. coli to CTX and other commonly used antibiotics could be due to poor adherence of patients to the prescribed medication as reported by some patients in this study.

The efficacy of CTX in areas of high bacterial resistance, its relative usefulness among individuals with differing CD4 cell counts, and the mechanisms through which it exerts its effects are unclear $[9,11]$. In this study, we could not establish the direct benefit of CTX prophylaxis in individuals with different levels of CD4 cell counts. To a greater extent this observation could have been contributed by the fact that majority of patients who were recruited in the study had already been initiated CTX prophylaxis before registration to the CTCs. Since these patients did not follow normal procedures for initiation of CTX prophylaxis at the CTCs, it is not known whether the patients were eligible to start prophylaxis based on the CD4 cell count. In addition, adherence to CTX prophylaxis during that time could not be ascertained. Another co-founding factor in this aspect could be due to non-adherence of patients to CTX prophylaxis even after enrolment at the CTCs as reported by one third of patients who admitted to have had skipped doses of CTX prophylaxis.

CTX prophylaxis might be a particularly useful intervention for people with no access to antiretroviral drugs and for those who are not yet eligible to start using antiretroviral drugs based on CD4 cell count. A recent randomised controlled trial in Senegal found no beneficial effect of CTX prophylaxis on mortality [28]. On the other hand, another study revealed that daily CTX prophylaxis was associated with 
reduced morbidity and mortality and had beneficial effects on CD4cell count and viral load [29]. In the present study, the occurrence of OIs was not in correlation with CD4 cell count levels among patients. However, CTX users were less likely to develop OIs as compared to nonusers. These findings indicate the need to monitor the use of CTX for prophylaxis of OIs. In order to ensure rational use of CTX prophylaxis, factors such as adherence, availability of CTX in the health facilities, self-medication and proper management of OIs should be part of HIV/ AIDS management program.

By preventing some OIs, CTX reduces the frequency of episodes of increased HIV viral load associated with acute illness, resulting in improved long-term CD4 cell response [30,31]. Increases in cytokine activity have been associated with a long-term decrease in CD4 cell count and increase in HIV viral load [32]. This is due to reactivation of the immune system by the presence of microbial and parasitic infections [33]. It has been reported that CTX prophylaxis exerts its effect partly through the reduction of transient increases in viral load and associated with CD4-cell count declines [34].

In this study, patients on CTX prophylaxis had relatively less likelihood of harbouring opportunistic pathogens as compared to those who were not on prophylaxis. Non-adherent patients were 1.17 times more likely to develop OIs as compare to adherent patients. In addition, the occurrence of OIs was associated with relatively higher rate of decrease in $\mathrm{CD} 4$ cell count over time. The pattern of occurrence of OIs in relationship with declining immunity in HIV/AIDS patients has also been reported by other researchers $[35,36]$. Our study could not establish an association between CTX prophylaxis and CD4 cell count due to the fact that majority of the patients were on CTX prophylaxis prior to enrolling into the CTX prophylaxis programme. Contrary to two previous reports which found that compliance with CTX prophylaxis regimens among HIV patients was excellent, our study shows about a third of the patients reported to have been nonadherent $[37,38]$.

CTX can cause several side-effects, especially in the intravenous formulation. The most common reactions are rash, fever, nausea, low white blood cells and liver inflammation. Skin rashes due to CTX are common among HIV-positive people $[17,39,40]$. Some of these were also reported by the interviewed patients in this study. These should be taken seriously and the drug withdrawn or the dose reduced because some people can develop Stevens-Johnson syndrome which is a potentially fatal allergic reaction [41]. However in this study, the treatment was very well tolerated, with only $14 \%$ of the patients reporting some mild side effects which were much less than those reported in other studies [42]. Moreover, these side effects could not be entirely correlated to CTX since some patients were also using anti-TB and antifungal drugs.

Analysis of CD4 cell counts and a number of OIs or their occurrence mong the patients showed no statistically significant differences in benefit of CTX prophylaxis. Because of limited data on level of immunosuppression other than CD4 counts, such as viral load or viremia, development of malignancies, and the observed problem of self-medication among PLHA; our study could not clearly suggest when to commence CTX prophylaxis. The privation of statistical association between CTX prophylaxis and mortality among individuals with higher CD cell counts has been reported elsewhere [24,37]. This could be due to variability of morbidity and/or mortality rates among individual patients; presumably as result of differences in HIV status and severity and number of OIs. In the present study, an association between CD4 cell count and the effect of CTX prophylaxis on mortality could not be determined due to limited time of study, patient follow up and small sample size.

Questions remain about the efficacy of CTX in areas of high bacterial resistance, its relative usefulness among individuals with differing CD4 cell counts, and the mechanisms through which it exerts its effect. CTX seems to significantly increase survival in HIV-infected patients on ART. Further research is needed to determine the optimum duration of CTX treatment in these patients. The observed high resistance of $E$. coli and other enterics to CTX and other commonly used antibiotics is of greater concern. This calls for immediate intervention in order to reassess the use of CTX for prophylaxis of OIs in Tanzania.

\section{Conclusions and Recommendations}

Majority (95.2\%) of the patients had initiated CTX prophylaxis prior to testing at the CTCs. This could have led to the high prevalence rate of E. coli resistance to CTX and other commonly used antibiotics. Resistance of $E$. coli to CTX was very high. In addition, resistance of $E$. coli to the commonly used antibiotics ciprofloxacin and ampicillin was also relatively high (53.2\%). Patients who were not on CTX prophylaxis had relatively higher possibility of contracting OIs. As shown in this study, TB is still the leading cause of morbidity in HIV patients in Tanzania. Therefore the use of CTX prophylaxis in HIV/AIDSpatients (in Tanzania) should be re-visited because of high antibacterial resistance revealed in this study.

Self-medication of CTX among HIV patients should be discouraged through counseling of the patients during their visits to the CTCs. HIV/ AIDS care providers in CTCs, should put in place adherence strategies to ensure that CTX is used rationally to maximize its benefits for prevention of OIs. For better understanding of the pattern of $E$. coli resistance to CTX and other commonly used antibiotics, phenotypic and/or genotypic characterization of the isolated bacteria needs to be carried out.

\section{Acknowledgements}

We acknowledge the financial support from Muhimbili University of Health and Allied Sciences and extend special appreciation to the municipal hospita management for granting permission to conduct the study in the hospitals. We also are grateful to the research assistants (Ms. Neema Kilimba and Mr. Godbless Godwin) for conducting interviews and collection of stool specimens from patients.

\section{References}

1. Fernández Guerrero ML, Ramos JM, Núñez A, Cuenca M, de Górgolas $M$ (1997) Focal infections due to non-typhi Salmonella in patients with AIDS: report of 10 cases and review. Clin Infect Dis 25: 690-697.

2. Gordon MA, Walsh AL, Chaponda M, Soko D, Mbvwinji M, et al. (2001) Bacteraemia and mortality among adult medical admissions in Malawipredominance of non-typhi salmonellae and Streptococcus pneumoniae. J Infect 42: 44-49.

3. Anglaret X, Chêne G, Attia A, Toure S, Lafont S, et al. (1999) Early chemoprophylaxis with trimethoprim-sulphamethoxazole for HIV-1-infected adults in Abidjan, Côte d'Ivoire: a randomised trial. Cotrimo-Cl Study Group. Lancet 353: 1463-1468.

4. Wiktor SZ, Sassan-Morokro M, Grant AD, Abouya L, Karon JM, et al. (1999) Efficacy of trimethoprim-sulphamethoxazole prophylaxis to decrease morbidity and mortality in HIV-1-infected patients with tuberculosis in Abidjan, Côte d'Ivoire: a randomised controlled trial. Lancet 353: 1469-1475.

5. Hamel MJ, Greene C, Chiller T, Ouma P, Polyak C, et al. (2008) Does cotrimoxazole prophylaxis for the prevention of HIV-associated opportunistic infections select for resistant pathogens in Kenyan adults? Am J Trop Med Hyg 79: $320-330$

6. Suthar AB, Lawn SD, del Amo J, Getahun H, Dye C, et al. (2012) Antiretroviral therapy for prevention of tuberculosis in adults with HIV: a systematic review and meta-analysis. PLoS Med 9: e1001270. 
Citation: Mwambete KD, Kamuhabwa AAR (2013) Resistance of Commensal Intestinal Escherichia Coli and Other Enterics to Co-trimoxazole and Commonly Used Antibiotics in HIV/AIDS Patients. Clin Microbial 3: 134. doi:10.4172/2327-5073.1000134

7. Kümmerer K (2004) Resistance in the environment. J Antimicrob Chemother 54: $311-320$.

8. Erb A, Stürmer T, Marre R, Brenner H (2007) Prevalence of antibiotic resistance in Escherichia coli: overview of geographical, temporal, and methodological variations. Eur J Clin Microbiol Infect Dis 26: 83-90.

9. BSAC Working Parties on Resistance Surveillance, Macgowan AP (2008) Clinical implications of antimicrobial resistance for therapy. J Antimicrob Chemother 62: ii105-114.

10. Balis E, Vatopoulos AC, Kanelopoulou M, Mainas E, Hatzoudis G, et al. (1996) Indications of in vivo transfer of an epidemic $R$ plasmid from Salmonella enteritidis to Escherichia coli of the normal human gut flora. J Clin Microbio 34: $977-979$.

11. Chiller TM, Poplak CS, Brooks JT, Williamson J, Ochieng B, et al. (2009) Daily trimethoprim-sulfamethoxazole prophylaxis rapidly induces corresponding resistance among intestinal Escherichia coli of HIV-infected adults in Kenya. J Int Assoc Physicians AIDS Care 8: 165-169.

12. Björkman J, Andersson DI (2000) The cost of antibiotic resistance from a bacterial perspective. Drug Resist Updat 3: 237-245

13. Health Action International (HAI), WHO report (2007) Monitoring Medicines in Tanzania-2007 Report.

14. Centre for Disease Control (2008) Antibiotic/antimicrobial resistance. The interagency task force on antimicrobial resistance and public health action plan. Annual Report 2008.

15. Amábile-Cuevas C (2010) Antibiotic resistance in Mexico: a brief overview of the current status and its causes. J Infect Dev Ctries 4: 126-131.

16. Albrich WC, Monnet DL, Harbarth S (2004) Antibiotic selection pressure and resistance in Streptococcus pneumoniae and Streptococcus pyogenes. Emerg Infect Dis 10: 514-517.

17. Forna F, McConnell M, Kitabire FN, Homsy J, Brooks JT, et al. (2006) Systematic review of the safety of trimethoprim-sulfamethoxazole for prophylaxis in HIVinfected pregnant women: implications for resource-limited settings. AIDS Rev 8: 24-36.

18. NCCLS-National Committee on Clinical Laboratory Standards (2003) Performance Standards for Antimicrobial Susceptibility Testing; Thirteenth Informational Supplement, NCCLS: Wayne, PA, USA.

19. CLSI-Clinical Laboratories Standards Institute (2006) Performance Standards for Antimicrobial Susceptibility Testing; Sixteenth Informational Supplement CLSI: Wayne, PA, USA

20. York MK, Baron EJ, Clarridge JE, Thomson RB, Weinstein MP (2000) Multilaboratory validation of rapid spot tests for identification of Escherichia coli. J Clin Microbiol 38: 3394-3398.

21. Cheesbrough M (2006) District Laboratory Practice in Tropical Countries. Part 2, Second Edition. Cambridge University Press The Edinburgh Building, Cambridge, CB2 8RU, UK.

22. Kaplan JE, Benson C, Holmes KH, Brooks JT, Pau A, et al. (2009) Guidelines for prevention and treatment of opportunistic infections in HIV-infected adults and adolescents: recommendations from CDC, the National Institutes of Health, and the HIV Medicine Association of the Infectious Diseases Society of America. MMWR Recomm Rep 58: 1-207.

23. Badri M, Ehrlich R, Wood R, Maartens G (2001) Initiating co-trimoxazole prophylaxis in HIV-infected patients in Africa: an evaluation of the provisional WHO/UNAIDS recommendations. AIDS 15: 1143-1148.

24. Initiative Evaluation Group in Côte d'Ivoire, Brou H, Desgrées-du-Loû $A$ Souville M, Moatti JP, Msellati P (2003) Prophylactic use of cotrimoxazole against opportunistic infections in HIV-positive patients: knowledge and practices of health care providers in Côte d'Ivoire. AIDS Care 15: 629-637.

25. Suthar AB, Granich R, Mermin J, Van Rie A (2012) Effect of cotrimoxazole on mortality in HIV-infected adults on antiretroviral therapy: a systematic review and meta-analysis. Bull World Health Organ 90: 128C-138C.
26. Mermin J, Were W, Ekwaru JP, Moore D, Downing R, et al. (2008) Mortality in HIV-infected Ugandan adults receiving antiretroviral treatment and survival of their HIV-uninfected children: a prospective cohort study. Lancet 371: 752-759.

27. Majalija S, Francis O, Sarah WG, Musisi-Lubowa, Vudriko P, et al. (2010) Antibiotic Susceptibility Profiles of Fecal Escherichia coli Isolates from DipLitter Broiler Chickens in Northern and Central Uganda. Veterinary Research 3: $75-80$.

28. Maynart M, Lièvre L, Sow PS, Kony S, Gueye NF, et al. (2001) Primary prevention with cotrimoxazole for HIV-1-infected adults: results of the pilot study in Dakar, Senegal. J Acquir Immune Defic Syndr 26: 130-136.

29. Mermin J, Lule J, Ekwaru JP, Malamba S, Downing R, et al. (2004) Effect of cotrimoxazole prophylaxis on morbidity, mortality, CD4-cell count, and viral load in HIV infection in rural Uganda. Lancet 364: 1428-1434.

30. Weissman D, Barker TD, Fauci AS (1996) The efficiency of acute infection of CD4+ T cells is markedly enhanced in the setting of antigen-specific immune activation. J Exp Med 183: 687-692.

31. Xiao L, Owen SM, Rudolph DL, Lal RB, Lal AA (1998) Plasmodium falciparum antigen-induced human immunodeficiency virus type 1 replication is mediated through induction of tumor necrosis factor. J Infect Dis 177: 437-445.

32. Salazar-Gonzalez JF, Martinez-Maza O, Nishanian P (1998) Increased immune activation precedes the inflection point of CD4 T cells and the increased serum virus load in human immunodeficiency virus infection. J Infect Dis 178: 423 430.

33. Mwambete KD, Justin-Temu M (2011) Poverty, Parasitosis and HIV/AIDS: major health concerns in Tanzania. In: Microbes, virues and parasites in AIDS process, 207-236.

34. Kaplan JE, Janoff EN, Masur H (1999) Editorial response: do bacteria pneumonia and Pneumocystis carinii pneumonia accelerate progression of human immunodeficiency virus disease? Clin Infect Dis 29: 544-546.

35. Chaisson RE, Gallant JE, Keruly JC, Moore RD (1998) Impact of opportunistic disease on survival in patients with HIV infection. AIDS 12: 29-33.

36. Anglaret $X$ (2001) Trimethoprim-sulfamethoxazole prophylaxis in sub-Saharan Africa. Lancet 358: 1027-1028.

37. Zachariah R, Spielmann MP, Chinji C, Gomani P, Arendt V, et al. (2003) Voluntary counselling, HIV testing and adjunctive cotrimoxazole reduces mortality in tuberculosis patients in Thyolo, Malawi. AIDS 17: 1053-1061.

38. Badri M, Maartens G, Wood R, Ehrlich R (1999) Co-trimoxazole in HIV-1 infection. Lancet 354: 334-335

39. van der Ven AJ, Vree TB, Koopmans PP, van der Meer JW (1996) Adverse reactions to co-trimoxazole in HIV infection: a reappraisal of the glutathionehydroxylamine hypothesis. J Antimicrob Chemother 37: 55-60.

40. Lin D, Li WK, Rieder MJ (2007) Cotrimoxazole for prophylaxis or treatment of opportunistic infections of HIVIAIDS in patients with previous history of hypersensitivity to cotrimoxazole. Cochrane Database Syst Rev, CD005646.

41. van Oosterhout JJ, Ndekha M, Moore E, Kumwenda JJ, Zijlstra EE, et al. (2010) The benefit of supplementary feeding for wasted Malawian adults initiating ART. AIDS Care 22: 737-742.

42. Rabaud C, Charreau I, Izard S, Raffi F, Meiffredy V, et al. (2001) Adverse reactions to cotrimoxazole in HIV-infected patients: predictive factors and subsequent HIV disease progression. Scand J Infect Dis 33: 759-764. 